\title{
POSICIONAMENTO ESTRATÉGICO E RESPONSABILIDADE SOCIAL CORPORATIVA: UM ESTUDO DE CASO EM AGROINDÚSTRIA SUCROALCOOLEIRA NO ESTADO DA PARAÍBA
}

\section{STRATEGIC POSITIONING AND CORPORATE SOCIAL RESPONSIBILITY: A CASE REPORT IN A SUGAR/ALCOHOL AGRIBUSINESS IN THE STATE OF PARAIBA}

\author{
Maria de Fátima Nóbrega Barbosa ${ }^{1}$; Gesinaldo Ataíde Cândido ${ }^{2}$ \\ ${ }^{1}$ Universidade Federal de Campina Grande - UFCG - Campina Grande - Brasil \\ mfnbarbosa@yahoo.com.br \\ ${ }^{2}$ Universidade Federal de Campina Grande - UFCG - Campina Grande - Brasil \\ gacandido@uol.com.br
}

\begin{abstract}
Resumo
Nos últimos anos, os aspectos relacionados aos problemas ambientais e à utilização dos recursos naturais passaram a ser uma preocupação das empresas tanto em termos de oportunidade para melhorar a sua forma de atuação, como oportunidade de negócios, como contribuir para a sustentabilidade. Neste sentido é que surgem os modelos e as ferramentas de gestão ambiental, dentre elas, a responsabilidade social corporativa, aplicada dentro de uma postura estratégica. Nesse contexto, o objetivo desse trabalho é identificar o posicionamento estratégico utilizado por uma destilaria de álcool, com vistas à responsabilidade social corporativa. Para o alcance desse objetivo, utilizou-se o modelo Estrutura-Conduta-Performance-Ambiental de Abreu (2011). Foi realizada uma pesquisa descritiva e de campo onde se realizou um estudo de caso numa destilaria de álcool no Estado da Paraíba. As técnicas utilizadas na pesquisa foram: pesquisa bibliográfica, entrevistas semi-estruturadas e observação não-participante. Os resultados constataram uma conduta ambiental intermediária da empresa e que, quando se correlaciona essa conduta ambiental com as pressões da estrutura da indústria, a empresa encontra-se num posicionamento estratégico ambiental oportunista.
\end{abstract}

Palavras-chave: Práticas Ambientais; Posicionamento Estratégico; Responsabilidade Social Corporativa.

\section{Introdução}

No contexto atual, o desempenho das empresas está cada vez mais atrelado às formas como respondem às pressões externas a que são submetidas quando da exigência por alcançarem, em seu sistema de negócios, um equilíbrio entre as dimensões econômicas, sociais e ambientais. Nesse contexto, muitas empresas estão incorporando em seu modelo de gestão indicadores ambientais 
presentes em vários modelos e ferramentas de gestão ambiental, pois começam a perceber que a competitividade depende cada vez mais de posturas responsáveis de sua parte no sentido de contribuírem na solução dos problemas ambientais e sociais.

A incorporação da variável ambiental na estrutura organizacional é cada vez mais premente, especialmente para empresas que desenvolvem muitas de suas atividades no mercado internacional, onde as exigências por parte dos governos e dos consumidores desses países no que se refere às questões socioambientais podem tornar-se fortes instrumentos de barreiras comerciais. (DEMAJOROVIC, 2003)

Desde o surgimento do desenvolvimento sustentável, a comunidade empresarial já não se encontra tão à vontade em ignorar a degradação causada pelos seus processos produtivos, o que coloca em risco a qualidade de vida das populações que encontram-se nas adjacências desses empreendimentos. Quanto mais degradante se apresentar uma determinada atividade, maiores serão as exigências por parte do governo, do estado e da sociedade no sentido de responsabilizar as empresas pelos danos causados ao meio ambiente.

Fatores diferenciados como regulamentações ambientais, reputação da empresa, pressões sociais e conscientização do consumidor contribuem para o grau de aproximação de uma empresa no tocante à incorporação da variável ambiental em seu processo de gestão, sendo que essas pressões podem tornar-se oportunidades para que as empresas incrementem a sua vantagem competitiva frente à concorrência. Porter e Linde (1995), em estudo pioneiro, mostram que as regulamentações ambientais conduzidas de forma apropriada apresentam potencialidade de provocar inovações, que se por um lado reduzem os custos totais de um produto, por outro contribuem para aumentar o seu valor, ao permitir que as empresas possam utilizar de forma mais produtiva insumos como matéria-prima, energia e mão-de-obra.

Desde o despertar do desenvolvimento sustentável, a sociedade civil, e particularmente as empresas, têm sido impelidas por pressões externas diversas a buscarem uma atitude proativa como forma de se posicionarem de forma ambientalmente responsável. Nesse contexto, este estudo parte da premissa de que as demandas das partes interessadas, os impactos ambientais e a legislação ambiental, aliados às práticas socioambientais, representam elementos de suma importância no sentido de contribuir para um posicionamento ambiental responsável.

A motivação para a incorporação de práticas socioambientais pelas empresas nem sempre é ativada pelos mesmos objetivos. Assim pergunta-se: quais os elementos que podem contribuir para que uma empresa possa alcançar um posicionamento estratégico responsável? Dessa forma, o objetivo desse trabalho é identificar o posicionamento estratégico ambiental utilizado por uma destilaria de álcool, com vistas à responsabilidade social corporativa. 
Em termos metodológicos, o estudo pode ser classificado como um estudo de caso exploratório e descritivo, utilizando métodos quantitativos para análise dos dados coletados para fazer a classificação da empresa quanto ao seu posicionamento estratégico ambiental com vistas à responsabilidade social corporativa; os modelos e as ferramentas de gestão ambiental foram utilizados como subsídios para entender o comportamento do posicionamento estratégico ambiental da empresa. Além da análise quantitativa, foram utilizadas técnicas qualitativas para análise de entrevistas com as pessoas diretamente envolvidas com as questões ambientais na empresa, além da análise de dados secundários e da observação não participante.

Além deste conteúdo introdutório, o trabalho apresenta nos itens seguintes: fundamentação teórica contemplando modelos e ferramentas de gestão ambiental; o modelo de Abreu (2001), pois apresenta uma metodologia que permite a avaliação do posicionamento estratégico de empresas, sendo o escolhido para ser utilizado neste estudo de caso; os procedimentos metodológicos e, posteriormente, são apresentados os resultados da pesquisa e as considerações finais.

\section{Fundamentação Teórica}

\subsection{Modelos e Ferramentas de Gestão Ambiental}

Vários modelos e ferramentas de gestão ambiental foram desenvolvidos e aprimorados como forma de contribuírem para uma postura ambientalmente responsável por parte dos atores sociais envolvidos com a atividade empresarial. A seguir serão explanados de forma sucinta os modelos e as ferramentas de gestão ambiental que serviram de suporte para compreender o posicionamento estratégico ambiental da empresa nessa pesquisa, tais como: o Sistema de Gestão Ambiental, a Produção Mais Limpa, a Ecoeficiência, a Auditoria Ambiental, a Avaliação de Impacto Ambiental, o Marketing Ambiental, a Educação Ambiental e a Responsabilidade Social Corporativa. A observância desses modelos nessa pesquisa se justifica, uma vez que o modelo que avalia o posicionamento estratégico desse estudo se utiliza de indicadores ambientais presentes em tais modelos e ferramentas ambientais.

Uma das formas de uma empresa estar inserida dentro do contexto ambiental é através da implantação de um Sistema de Gestão Ambiental ( $S G A)$. Ao implantar um SGA, a empresa toma consciência dos impactos ambientais negativos que as suas atividades podem provocar no ambiente externo em que ela encontra-se inserida. A definição desenvolvida pela Associação Brasileira de Normas Técnicas em relação ao sistema de gestão ambiental é que o mesmo pode ser definido como “a parte de um sistema da gestão de uma organização utilizada para desenvolver e implementar sua política ambiental e para gerenciar seus aspectos ambientais” (ABNT, 2004, p. 2). 
A Produção Mais Limpa surge como resposta às práticas de tratamento e controle da poluição conhecidas como tecnologias fïm de tubo; são práticas consideradas caras, que não agregam vantagens competitivas para as organizações que fazem uso delas. De acordo com Barbieri (2007, p. 134), a Produção Mais Limpa (P + L) representa "uma estratégia ambiental preventiva aplicada a processos, produtos e serviços para minimizar os impactos sobre o meio ambiente". O autor em comento ainda faz alusão a um conceito de Produção Mais Limpa elaborado num seminário pelo PNUMA, onde se refere a $\mathrm{P}+\mathrm{L}$ sob um enfoque mais abrangente em que procura observar em sua operacionalização todas as etapas do ciclo de vida do produto vislumbrando reduzir riscos para os seres humanos e o meio ambiente num horizonte de curto e longo prazos.

A Ecoeficiência entrou para o cenário empresarial em 1992 através do Business Council for SustainableDevelopment, hoje denominado World Business Council for SustainableDevelopment(WBCSD). Para a OCDE e a WBCSD, a ecoeficiência é atingida quando se coloca a disposição da sociedade produtos e serviços dotados de preços competitivos capazes de atenderem às necessidades humanas trazendo ganhos para a qualidade de vida, ao tempo em que diminuem de forma contínua impactos ambientais negativos e o uso dos recursos considerando-se todo o ciclo de vida desses bens e serviços. Todo esse esforço com o escopo maior de se conservar a capacidade suporte do Planeta (ORGANISATION FOR ECONOMIC CO-OPERATION AND DEVELOPMENT, In: BARBIERI, 2007).

Conforme Philippi Jr. e Aguiar (2004), as auditorias ambientais surgiram da necessidade de empresas multinacionais obterem informações sobre a postura ambiental praticada por suas filiais, uma vez não desejarem que a imagem corporativa seja alvo de críticas por alguma atitude danosa ao meio ambiente praticada pelas filiais. La Rovere (2001) faz referência às inúmeras vantagens e a algumas desvantagens que se podem observar da prática da auditoria ambiental pelas empresas. Algumas vantagens seriam: identificação e registro das conformidades e das não-conformidades com a legislação, com regulamentações e normas e com a política ambiental da empresa (caso exista); prevenção de acidentes ambientais; melhor imagem da empresa junto ao público, à comunidade e ao setor público; assessoramento aos gestores na implementação da qualidade ambiental na empresa; avaliação, controle e redução do impacto ambiental da atividade; minimização dos resíduos gerados e dos recursos usados pela empresa. As desvantagens seriam: mitigar a possibilidade de ocorrer um acidente ambiental e da empresa não atender aos requisitos legais de proteção ambiental; deve ser aplicada com frequência regular (mínima anual), estar inserida em um programa de gestão ambiental da empresa e ter garantida a implementação, por parte da empresa, das medidas corretivas das não-conformidades identificadas.

A Avaliação de Impacto Ambiental (AIA) representa um instrumento de gestão ambiental de cunho analítico, preventivo e que complementa o processo de licenciamento ambiental, tendo 
por escopo mitigar os impactos ambientais negativos em relação ao meio ambiente. De acordo com Seiffert (2007), na AIA estão inseridas diversas funções relevantes para o processo de gestão ambiental, que podem ser resumidas da seguinte forma: informações úteis ao poder público no sentido de auxiliá-lo na implantação de novos empreendimentos; controle e consciência ambiental (da sociedade e da administração pública); qualidade de vida e ambiental; educação participativa e cidadã. Sánchez (2006), ao tratar da Avaliação de Impacto Ambiental, traz uma visão alargada dessa ferramenta ao considerá-la inserida não só no planejamento ambiental, mas também na gestão ambiental, ou seja, ele mostra que a AIA precisa estar integrada nas dimensões de planejamento e gestão para que o seu real potencial de aplicação se realize.

O Marketing Ambiental surge como uma ferramenta apropriada no sentido de imprimir uma imagem diferenciada da empresa junto aos stakeholders (sociedade, fornecedores, clientes internos e externos, mercado).Com o propósito de estar em sintonia com os princípios do desenvolvimento sustentável, Dias (2007) enuncia algumas funções que caberia ao marketing ambiental desempenhá-las, quais sejam: função informativa acerca do conteúdo ambiental inserido nos processos produtivos; função educativa atrelada ao processo informacional da empresa, gerando consumidores mais conscientes do seu papel em relação ao cuidado com o meio ambiente; função de incentivo a atitudes propiciadoras do bem-estar do meio ambiente, a exemplo da reciclabilidade de material; mudanças de comportamentos individuais e da sociedade que sejam degradadores das condições ambientais.

No que se refere à Educação Ambiental na empresa, Simons (2006) chama a atenção da importância dessa ferramenta na medida em que a mesma seja utilizada em sua dimensão transformadora e não simplesmente de forma pontual e esporádica. Faz-se mister que a educação ambiental em sua forma plena seja internalizada no âmago da empresa por meio de diálogos onde cada um, independente de sua posição hierárquica, tenha consciência sistêmica de todos os processos sustentáveis envolvidos e que essa percepção seja extrapolada para além muros organizacionais.

Apesar da importância que tem alcançado nas últimas décadas, a operacionalidade da responsabilidade social ainda não é bem compreendida no mundo empresarial. Seu conceito tem gerado conflitos e insegurança por parte dos empresários sobre como inseri-la nas atividades diárias da empresa. Dessa forma, surgiram diversos modelos com o propósito de representar a responsabilidade social corporativa, quais sejam: o modelo de Quazi e O'Brien (2000), o modelo de Enderle e Tavis (1998), o modelo de Wood (1991), o modelo de Carrol (1999).Borger (2006), por sua vez, referencia os autores Carroll (1999), Frederick, Wartick e Crochan (1996), Donaldson e Preston, no sentido de mostrar os modelos de responsabilidade social que foram se aprimorando 
para dar respostas à comunidade empresarial em relação a como colocar em prática a gestão da Responsabilidade Social Empresarial (SER).

Assim, Carroll passa a admitir um modelo no qual a RSE vai se apoiar nas dimensões econômica, legal, ética e filantrópica com o intuito de integrar empresa e sociedade. Entretanto, o modelo sofre críticas, entre as quais não dar respostas efetivas para se orientar a postura social das empresas. Surge o modelo de responsividade corporativa, de Frederick, tendo por missão dar respostas responsáveis aos variados problemas que se apresentam à empresa no dia a dia; representa, pois, o ajustamento da conduta empresarial às exigências sociais. A crítica ao modelo surge do fato de o mesmo não dar respostas para melhorar o mundo, pois sua preocupação maior está na sobrevivência da empresa no momento atual; apresenta, pois, visão de curto prazo. Wartick e Crochan (1996) vão além do modelo anterior e propõem um modelo que traz preocupação com o desempenho social, no qual o desempenho pode ser identificado e mensurado. Não obstante, o modelo ainda apresenta obstáculos para ser efetivamente colocado em prática. Assim, o modelo que se propõe para a atualidade, em consonância aos princípios do desenvolvimento sustentável, é o modelo representado pela teoria do stakeholder tendo, por entendimento que a responsabilidade social deve ser definida em relação aos grupos de interesses que impactam a postura das organizações ou são impactados por ela.(BORGER, 2006).

O modelo do stakeholder fundamenta-se numa perspectiva sistêmica da organização na sociedade; dessa forma, as relações entre as empresas e a sociedade apresentam-se intimamente relacionadas e dessa relação surge o capital social, intelectual, financeiro e ambiental que garantirá a sustentabilidade e o crescimento da organização. Esse conceito encontra-se em consonância com os benefícios apresentados por Froes e Melo Neto (1999) quando da adoção desse modelo pela organização, tais como: suporte ao desenvolvimento da comunidade; preservação do meio ambiente; investimento no bem-estar de funcionários, dependentes e ambiente de trabalho; transparência nas comunicações; integração com parceiros; satisfação dos clientes.

Pelo exposto percebe-se uma variedade de modelos e ferramentas de gestão ambiental que podem estar contemplados na estratégia das empresas. O modelo Estrutura-Conduta-PerformanceAmbiental (ECP-Ambiental de Abreu (2001) ao considerar em sua estrutura as demandas das partes interessadas, os impactos ambientais do processo produtivo e a legislação ambiental, e ainda por agregar indicadores de modelos ambientais como o Sistema de Gestão Ambiental, a Produção Mais Limpa e a Responsabilidade Social Corporativa, bem como indicadores presentes nas ferramentas ambientais: ecoeficiência, avaliação de impactos ambientais, auditoria ambiental, avaliação de impacto ambiental e educação ambiental foi o escolhido com meio de identificar o posicionamento estratégico da empresa desse estudo de caso, tendo em vista a responsabilidade social corporativa. Dessa forma, será exposto de forma detalhada no item a seguir. 


\subsection{O modelo Estrutura-Conduta-Performance-Ambiental (ECP-Ambiental de Abreu (2001)}

Abreu (2001) apresenta um modelo de avaliação da estratégia ambiental, denominado Modelo Estrutura-Condudta-Performance- Ambiental (ECP-Ambiental), que propicia saber quais as pressões da estrutura da indústria com relação à conduta ambiental. Além do mais, representa uma ferramenta mais robusta de planejamento ambiental estratégico para auxiliar a tomada de decisão. Esse modelo faz parte de um modelo mais abrangente de mesma autoria denominado EstruturaConduta-Performance -Triplo (ECP-Triplo), com o escopo de evidenciar um resultado final triplo, onde os resultados sociais e ambientais são elevados à mesma posição dos econômicos.

O ECP-Triplo e o ECP-Ambiental tomam como subsídio para o seu desenvolvimento o modelo Estrutura-Conduta-Performance de Scherer e Ross (1990) apresentando como princípio norteador que a performance de uma empresa é o resultado de suas práticas competitivas ou padrões de conduta, que se encontram por seu turno, atrelados à estrutura de mercado em que a empresa está inserida. Os modelos ECP-Triplo e por extensão o ECP-Ambiental, trazem de Elkington (1999) a idéia de que é possível por parte das empresas ligarem as três dimensões do desenvolvimento sustentável (econômica, social e ambiental) às suas estratégias de negócio.

O modelo ECP-Ambiental procura entender a qualidade da gestão ambiental na empresa observando como se comporta o seu sistema de negócios nas áreas estratégicas: pesquisa e desenvolvimento, compras, produção e manutenção, administração (geral, financeira, jurídica e de recursos humanos), marketing e distribuição. Assim, um conjunto de indicadores de conduta ambiental foi construído para refletir a qualidade ambiental da gestão empresarial. Para a definição dos indicadores de conduta ambiental se utilizou os requisitos da ISO 14001 (1996) onde se pode observar as especificações e diretrizes para a implantação e o uso do Sistema de Gestão Ambiental.

Os indicadores de performance ambiental foram construídos com base no modelo PressãoEstado-Resposta - PSR (OECD, 1998), uma vez que os critérios utilizados para a definição dos indicadores abarcam mensurabilidade, utilidade, funcionalidade analítica e relevância, além de propiciar melhor tomada de decisão por permitir integração das preocupações ambientais com políticas setoriais.

Para as diversas áreas estratégicas da empresa, a sistemática utilizada para a escolha dos indicadores de conduta ambiental pode ser exposta como segue.

A função pesquisa e desenvolvimento contemplam a análise do ciclo de vida dos produtos através dos selos verdes e a adoção de tecnologias limpas no processo produtivo; na função produção e manutenção identificam-se os aspectos e impactos ambientais e os controles operacionais dos aspectos ambientais considerados relevantes; a administração geral procura averiguar a política ambiental, a definição das responsabilidades na estrutura organizacional, o 
planejamento dos objetivos e metas, a documentação e o controle dos documentos; na função administração financeira procura-se averiguar os investimentos na área ambiental propícios ao cumprimento da legislação ambiental; esta por sua vez observada pela função administração jurídico; cabe à administração de recursos humanos definir um programa de educação ambiental no sentido de conscientizar os colaboradores da importância de se cumprir a política ambiental, bem como os objetivos e as metas; ao marketing cabe o papel de averiguar os meios de comunicação com as partes interessadas e seus requisitos ambientais; a função distribuição considera os canais de distribuição e o gerenciamento dos riscos associados ao transporte dos produtos.

Esse modelo, tomando por referência o modelo de Post e Altman (1994) conforme Abreu (2001), ainda classifica a conduta ambiental em três perfis quando da interpretação dos dados, quais sejam: conduta fraca, intermediária e forte. Uma conduta ambiental forte significa a existência de uma avaliação quantitativa da sua medida da performance ambiental. Numa conduta ambiental intermediária, a empresa está apenas começando o processo de quantificação da performance ambiental. Por sua vez, uma empresa com uma conduta ambiental fraca não realiza a quantificação da performance ambiental.

Os parâmetros adotados pela autora para classificar as empresas com uma conduta ambiental forte, intermediária e fraca estão expostos no Quadro 1. Esses parâmetros foram construídos de acordo com os indicadores adotados no modelo ECP-Ambiental para as condutas ambientais.

Quadro 1 - Matriz de características de conduta ambiental das empresas

\begin{tabular}{|c|c|c|c|}
\hline Funções Gerenciais & Conduta ambiental fraca & $\begin{array}{l}\text { Conduta ambiental } \\
\text { intermediária }\end{array}$ & $\begin{array}{c}\text { Conduta ambiental } \\
\text { forte }\end{array}$ \\
\hline $\begin{array}{l}\text { Administração } \\
\text { Geral }\end{array}$ & $\begin{array}{l}\text { Não existe } \\
\text { gerência/departamento } \\
\text { ambiental na estrutura } \\
\text { organizacional com as } \\
\text { atribuições distribuídas. O } \\
\text { nível gerencial é o mais } \\
\text { alto para o trato das } \\
\text { questões ambientais. Não } \\
\text { assume compromissos } \\
\text { formais em uma política } \\
\text { ambiental. A importância } \\
\text { da questão ambiental está } \\
\text { limitada ao atendimento } \\
\text { dos condicionantes da } \\
\text { licença de operação }\end{array}$ & $\begin{array}{l}\text { Existe um responsável } \\
\text { dentro da estrutura } \\
\text { organizacional. A } \\
\text { diretoria é o nível mais } \\
\text { alto para o trato das } \\
\text { questões ambientais. } \\
\text { Existem compromissos } \\
\text { formais estabelecidos } \\
\text { na política ambiental. A } \\
\text { importância da questão } \\
\text { não está limitada ao } \\
\text { atendimento à } \\
\text { legislação ambiental. } \\
\text { Preocupadas com a } \\
\text { imagem e em alcançar } \\
\text { novos mercados. }\end{array}$ & $\begin{array}{l}\text { Existe uma } \\
\text { gerência/departamento } \\
\text { de meio ambiente na } \\
\text { estrutura } \\
\text { organizacional. As } \\
\text { questões ambientais são } \\
\text { tratadas em nível de } \\
\text { presidência. Existem } \\
\text { compromissos formais } \\
\text { em atender à legislação, } \\
\text { melhoria contínua dos } \\
\text { processos e prevenção } \\
\text { da poluição. } \\
\text { importância da questão } \\
\text { está vinculada ao } \\
\text { compromisso com o } \\
\text { desenvolvimento } \\
\text { sustentável. } \\
\text { Preocupados com a } \\
\text { imagem da empresa }\end{array}$ \\
\hline
\end{tabular}




\begin{tabular}{|c|c|c|c|}
\hline $\begin{array}{l}\text { Administração } \\
\text { Jurídico }\end{array}$ & $\begin{array}{l}\text { Não conhece a legislação } \\
\text { ambiental e não possui } \\
\text { instrumentos } \\
\text { acompanhá-la }\end{array}$ & $\begin{array}{l}\text { Conhece parcialmente a } \\
\text { legislação ambiental. O } \\
\text { acompanhamento do } \\
\text { atendimento à } \\
\text { legislação é realizado } \\
\text { de forma não } \\
\text { sistemática pelo } \\
\text { responsável pela área } \\
\text { de meio ambiente. }\end{array}$ & $\begin{array}{l}\text { Conhece integralmente } \\
\text { a legislação. Contrata } \\
\text { consultoria externa para } \\
\text { a sua atualização. O } \\
\text { acompanhamento do } \\
\text { atendimento à } \\
\text { legislação é realizado } \\
\text { pela gerência de meio } \\
\text { ambiente e o jurídico. }\end{array}$ \\
\hline $\begin{array}{l}\text { Administração } \\
\text { Financeiro }\end{array}$ & $\begin{array}{l}\text { Os investimentos } \\
\text { ambientais representam de } \\
0 \text { a } 1 \% \text { dos investimentos } \\
\text { totais. Definidos para } \\
\text { atender à legislação } \\
\text { ambiental. Os ganhos } \\
\text { financeiros estão atrelados } \\
\text { às vendas de resíduos e } \\
\text { subprodutos sem alteração } \\
\text { do processo produtivo. } \\
\text { Não consegue } \\
\text { dimensionar esses ganhos. }\end{array}$ & $\begin{array}{l}\text { Os investimentos } \\
\text { representam entre } 1 \text { a } 2 \\
\% \text { dos investimentos } \\
\text { totais. Definidos com } \\
\text { base nos projetos } \\
\text { gerados internamente } \\
\text { de forma espontânea. } \\
\text { Os ganhos financeiros } \\
\text { estão atrelados à } \\
\text { redução do desperdício, } \\
\text { relacionada aos } \\
\text { insumos água e energia, } \\
\text { e à comercialização dos } \\
\text { resíduos. }\end{array}$ & \begin{tabular}{lrr} 
Os & \multicolumn{2}{r}{ investimentos } \\
representam & mais de 2 \\
$\%$ & dos & investimentos \\
totais da & empresa. \\
Definidos com & base nos \\
objetivos & e & metas \\
ambientais. Os & ganhos \\
financeiros & estão \\
atrelados à redução das \\
perdas de rocesso. \\
Podem rarir \\
investimentos \\
ambientais sem retorno \\
financeiro.
\end{tabular} \\
\hline $\begin{array}{l}\text { Administração } \\
\text { Recursos Humanos }\end{array}$ & $\begin{array}{l}\text { Não existe um programa } \\
\text { de educação ambiental. }\end{array}$ & $\begin{array}{l}\text { Possui um programa de } \\
\text { educação ambiental } \\
\text { voltado para ações } \\
\text { básicas como a coleta } \\
\text { seletiva de lixo, e } \\
\text { desenvolvido } \\
\text { informalmente através } \\
\text { de palestras. Frequência } \\
\text { anual. }\end{array}$ & 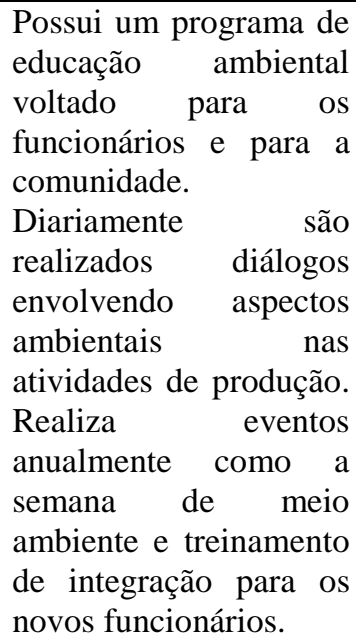 \\
\hline $\begin{array}{l}\text { Desenvolvimento de } \\
\text { produtos } \\
\text { processo }\end{array}$ & $\begin{array}{l}\text { Não adota tecnologias } \\
\text { para minimizar o impacto } \\
\text { ambiental. }\end{array}$ & $\begin{array}{l}\text { Investe na aquisição de } \\
\text { equipamentos com um } \\
\text { menor consumo de } \\
\text { insumos. }\end{array}$ & $\begin{array}{l}\text { Desenvolve tecnologias } \\
\text { para minimizar o } \\
\text { impacto ambiental de } \\
\text { seus processos } \\
\text { produtivos. Produtos } \\
\text { certificados com o selo } \\
\text { verde. }\end{array}$ \\
\hline Compras & 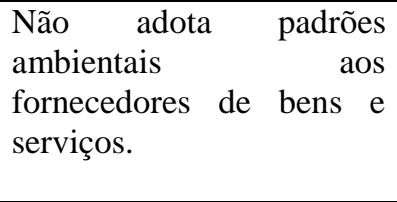 & $\begin{array}{l}\text { Adota parcialmente } \\
\text { padrões ambientais aos } \\
\text { seus fornecedores de } \\
\text { serviços. }\end{array}$ & $\begin{array}{l}\text { Adota padrões } \\
\text { ambientais para a } \\
\text { qualificação de todos os } \\
\text { seus fornecedores de } \\
\text { bens e serviços. }\end{array}$ \\
\hline $\begin{array}{l}\text { Produção } \\
\text { manutenção }\end{array}$ & $\begin{array}{l}\text { Não possui um sistema de } \\
\text { gestão ambiental. Não } \\
\text { avalia os impactos } \\
\text { ambientais de suas } \\
\text { atividades, produtos e } \\
\text { serviços. Não realiza } \\
\text { auditorias ambientais. Os }\end{array}$ & $\begin{array}{l}\text { Está em processo de } \\
\text { implementação de um } \\
\text { sistema de gestão } \\
\text { ambiental. Avalia os } \\
\text { impactos ambientais de } \\
\text { suas atividades, } \\
\text { produtos e serviços. }\end{array}$ & $\begin{array}{l}\begin{array}{l}\text { Possui um sistema de } \\
\text { gestão }\end{array} \\
\text { ambiental } \\
\text { certificado pela NRB } \\
\text { ISO 14001. Faz o } \\
\text { levantamento } \\
\text { avaliação dos aspectos } \\
\text { e impactos ambientais }\end{array}$ \\
\hline
\end{tabular}




\begin{tabular}{|c|c|c|c|}
\hline & \begin{tabular}{lrr} 
controles & \multicolumn{2}{c}{ operacionais } \\
atrelados aos insumos da \\
produção. Não adota uma \\
sistemática de melhoria \\
contínua & para & os \\
indicadores & & de \\
performance. &
\end{tabular} & $\begin{array}{lrr}\text { Processo } & \text { imaturo de } \\
\text { auditorias } & \text { ambientais } \\
\text { semestrais. } & \text { Controles } \\
\text { operacionais } & \text { atrelados } \\
\text { aos insumos } & \text { de } \\
\text { processo e } & \text { o } \\
\text { atendimento } & \text { da } \\
\text { legislação ambiental. } \\
\text { Os indicadores } \\
\text { ambientais ran } \\
\text { estabelecidos através } \\
\text { dos padrões legais. Não } \\
\text { existe uma sistemática } \\
\text { de melhoria contínua } \\
\text { dos indicadores de } \\
\text { performance, apenas } \\
\text { conformidade legal. }\end{array}$ & $\begin{array}{l}\text { de suas atividades, } \\
\text { produtos e serviços. } \\
\text { Realiza auditorias } \\
\text { ambientais internas. Os } \\
\text { indicadores ambientais } \\
\text { foram estabelecidos } \\
\text { com base nos padrões } \\
\text { legais e em comparação } \\
\text { com outras unidades da } \\
\text { empresa ou histórico de } \\
\text { desempenho. Adota } \\
\text { uma sistemática de } \\
\text { melhoria contínua dos } \\
\text { indicadores ambientais. }\end{array}$ \\
\hline Marketing & 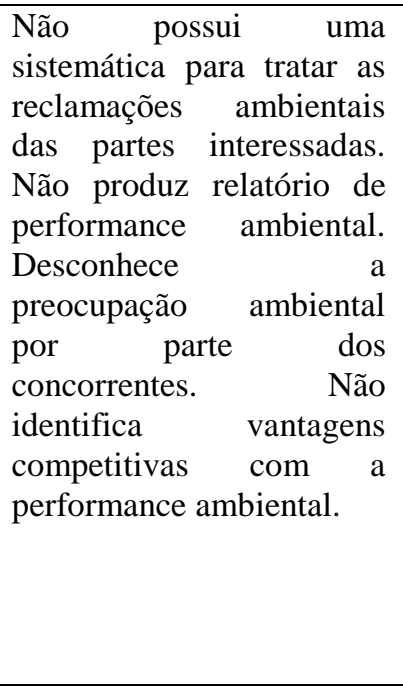 & $\begin{array}{l}\text { Utiliza a sistemática de } \\
\text { atendimento ao cliente } \\
\text { para tratamento das } \\
\text { reclamações das partes } \\
\text { interessadas. Não } \\
\text { produz relatórios de } \\
\text { performance ambiental. } \\
\text { Percebe a preocupação } \\
\text { ambiental de seus } \\
\text { concorrentes. Está } \\
\text { começando a identificar } \\
\text { algumas vantagens } \\
\text { competitivas com a } \\
\text { questão ambiental. }\end{array}$ & 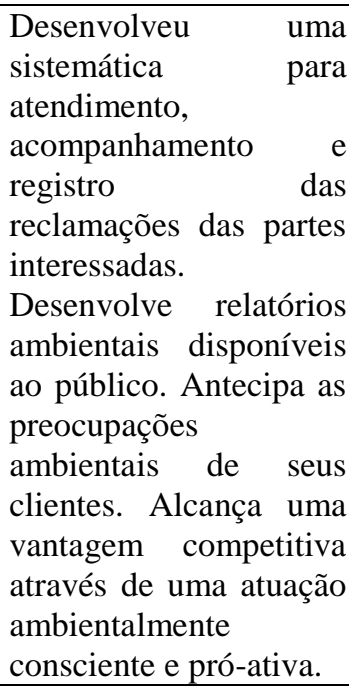 \\
\hline Distribuição & $\begin{array}{l}\text { Não identifica os riscos } \\
\text { ambientais na distribuição } \\
\text { de seus produtos. }\end{array}$ & $\begin{array}{lrr}\text { Identifica } & \text { riscos } & \text { de } \\
\text { acidentes } & & \text { na } \\
\text { distribuição de } & \text { seus } \\
\text { produtos. Adota } & \text { alguns } \\
\text { critérios } & \text { para } \\
\text { distribuição } & \text { de } \\
\text { produtos. } & \end{array}$ & $\begin{array}{lr}\text { Adota } & \text { critérios } \\
\text { rigorosos de prevenção } \\
\text { da poluição } & \text { para } \\
\text { distribuição dos } & \text { seus } \\
\text { produtos. } & \text { Adota } \\
\text { medidas preventivas } & \text { para evitar acidentes. }\end{array}$ \\
\hline
\end{tabular}

Fonte: Abreu (2001, p. 173)

O Modelo ECP-Ambiental, ao observar a conduta ambiental da empresa, bem como as pressões existentes no ambiente em que está inserida, permite que se chegue por meio de uma correlação entre essas variáveis aos seguintes posicionamentos estratégicos: derrotada, sofrível, responsável, indiferente, oportunista ou pioneira.

Sendo as pressões da indústria representadas pelos impactos ambientais inerentes ao processo produtivo, pela legislação ambiental e pelas exigências ambientais das partes interessadas, o modelo ainda adota os seguintes critérios para classificar uma pressão como alta ou baixa, conforme Quadro 2. 
Quadro 2 - Pressão da estrutura da indústria

\begin{tabular}{|l|l|l|}
\hline \multirow{2}{*}{$\begin{array}{c}\text { Características da Estrutura } \\
\text { da Indústria }\end{array}$} & \multicolumn{1}{c|}{ Alta } \\
\cline { 2 - 3 } & \multicolumn{1}{c|}{ Pressão } \\
\hline $\begin{array}{l}\text { Impacto ambiental inerente ao } \\
\text { processo produtivo e variável } \\
\begin{array}{l}\text { com a escala de produção e a } \\
\text { tecnologia adotada }\end{array}\end{array}$ & $\begin{array}{l}\text { Alto impacto ambiental das } \\
\text { atividades, produtos ou serviços }\end{array}$ & $\begin{array}{l}\text { Baixo impacto ambiental das } \\
\text { atividades, produtos ou serviços }\end{array}$ \\
\hline Legislação Ambiental & $\begin{array}{l}\text { Regulamentação rígida e } \\
\text { fiscalização atuante }\end{array}$ & $\begin{array}{l}\text { Regulamentação e fiscalização } \\
\text { incipientes }\end{array}$ \\
\hline $\begin{array}{l}\text { Exigências Ambientais das } \\
\text { Partes Interessadas }\end{array}$ & Exigências reais & Exigências potenciais \\
\hline
\end{tabular}

Fonte: Abreu (2001. p.195)

A Figura 1 expõe o posicionamento estratégico a que as empresas estão sujeitas quando se correlaciona sua conduta ambiental com as pressões do seu ambiente de atuação.

Figura 1 - Matriz de correlação entre a pressão da estrutura da indústria e a conduta ambienta

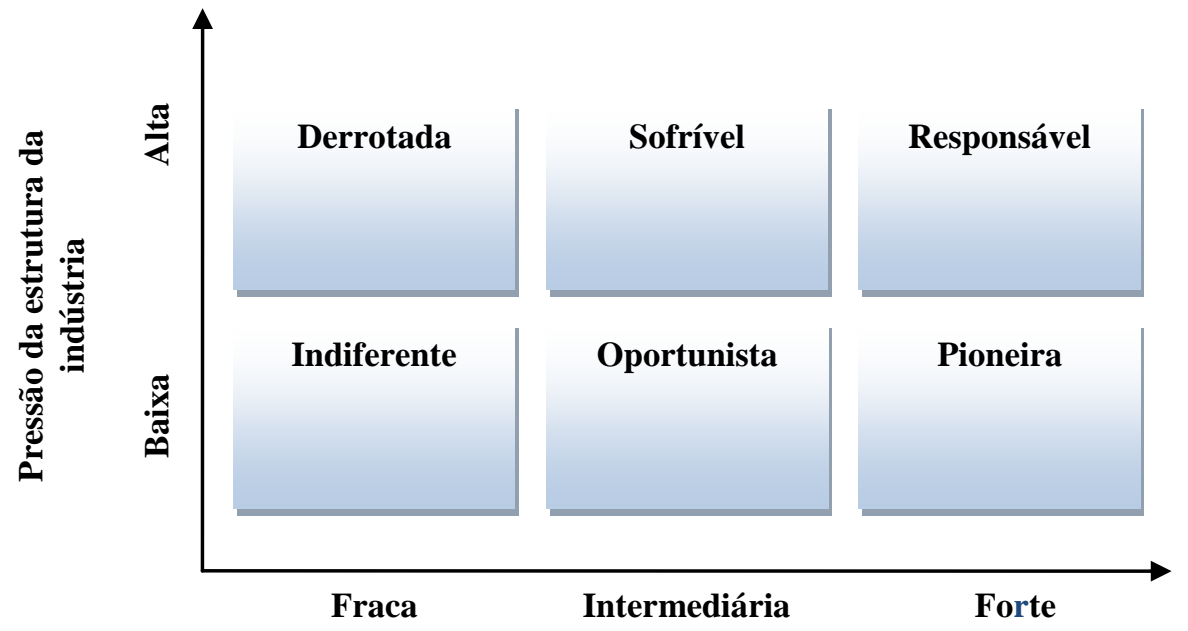

Conduta Ambiental

Fonte: Abreu (2001, p. 191)

Conforme o modelo de Abreu (2001), quando as empresas apresentam uma conduta ambiental forte e estão submetidas a altas pressões da estrutura da indústria comportam-se de forma responsável em prol de uma conduta ambiental superior que irão lhes proporcionar vantagens competitivas.

\section{Procedimentos Metodológicos}

A metodologia utilizada para a realização do trabalho utilizou-se da seguinte sistemática: realização de um estudo de caso numa destilaria de álcool no Estado da Paraíba, no sentido de identificar o posicionamento estratégico ambiental utilizado pela empresa com vistas à responsabilidade social corporativa. Os modelos e as ferramentas de gestão ambiental foram utilizados como subsídios para entender o comportamento do posicionamento estratégico ambiental da empresa. Para o tratamento 
dos dados adotou-se a análise quantitativa e qualitativa e os instrumentos de coleta de dados foram a observação não participante, entrevistas semi-estruturadas com os analistas do meio ambiente da empresa e aplicação de formulário.

Quanto ao método de procedimento, esta pesquisa se utilizou de um estudo de caso único e holístico (uma unidade única de análise) numa destilaria de álcool do Estado da Paraíba. O método estudo de caso, conforme Yin (2005, p.32) "investiga um fenômeno contemporâneo dentro de seu contexto da vida real, especialmente quando os limites entre o fenômeno e o contexto não estão claramente definidos".

Quanto aos fins: foi uma pesquisa exploratória e descritiva. Quanto aos meios: tratou-se de uma pesquisa bibliográfica e de campo. (VERGARA, 1997).

A análise da conduta ambiental da empresa nessa pesquisa, além dos parâmetros definidos por Abreu (2001) para sua avaliação, também adotou uma escala para mensuração dessa conduta conforme descritos no Quadro 3.

\begin{tabular}{|c|c|c|c|c|c|c|}
\hline \multicolumn{7}{|c|}{ Quadro 3- Parâmetros e pesos para análise da conduta ambiental } \\
\hline \multirow{2}{*}{ FRACA } & \multirow{2}{*}{ FONDUTAS } \\
\cline { 1 - 1 } Muito Fraca & Fraca & $\begin{array}{c}\text { Tendência a } \\
\text { Intermediária }\end{array}$ & $\begin{array}{c}\text { INEDIÁ } \\
\text { RIA }\end{array}$ & $\begin{array}{c}\text { Tendência } \\
\text { a Conduta } \\
\text { Intermediár } \\
\text { ia }\end{array}$ & Forte & Muito Forte \\
\hline$-1,0$ a $-0,8$ & $-0,7$ a $-0,4$ & $-0,3$ a $-0,1$ & 0,0 & 0,1 a 0,3 & 0,4 a 0,7 & 0,8 a 1,0 \\
\hline
\end{tabular}

Fonte: Adaptado de Abreu (2001)

A performance ambiental foi analisada por meio de variáveis observando os compartimentos ambientais: água, ar, solo, fauna, flora e recursos naturais. Para cada compartimento também foram definidos os indicadores de avaliação. A performance foi avaliada observando-se dois períodos como forma de avaliar o desempenho ambiental da empresa nesse intervalo.

A pressão da estrutura da indústria foi definida observando-se o impacto ambiental inerente ao processo produtivo, à legislação ambiental e às exigências ambientais das partes interessadas.

Os resultados e a discussão da conduta ambiental serão realizados observando-se os parâmetros descritos no quadro acima.

\section{Apresentação e Análise dos Resultados}

\subsection{Conduta Ambiental da Empresa Estudo de Caso}

Utilizando-se a metodologia de Abreu (2001), os principais resultados da pesquisa para a conduta ambiental podem ser apresentados na Tabela 1. 
Tabela 1 - Avaliação da Conduta Ambiental da Empresa

\begin{tabular}{l|lr}
\hline \multicolumn{1}{c|}{ FUNÇÕES GERENCIAIS } & \multicolumn{1}{c}{ CONDUTA AMBIENTAL } & MÉDIA \\
\hline Administração Geral & Intermediária & 0,0 \\
Administração Jurídica & Forte & 0,5 \\
Administração Financeira & Tendência a Intermediária & $-0,3$ \\
Administração Recursos Humanos & Intermediária & 0,0 \\
Pesquisa e Desenvolvimento & Intermediária & 0,0 \\
Compras & Forte & 0,5 \\
Produção e Manutenção & Tendência à Conduta Intermediária & 0,3 \\
Marketing & Tendência à Conduta Intermediária & 0,3 \\
Distribuição & Conduta Intermediária & 0,0 \\
\hline MÉDIA GERAL & Tendência a Conduta Intermediária & 0,1 \\
\hline
\end{tabular}

Fonte: Pesquisa de campo (2009)

A conduta ambiental para a função gerencial administração geral pode ser indicada como intermediária, uma vez que ainda não dispõe de uma política ambiental escrita. A política ambiental representa o ponto de partida para que uma organização implemente e aperfeiçoe o seu de gestão ambiental. Faz-se necessário ainda que esta seja comunicada para todas as pessoas que trabalhem direta ou indiretamente com a empresa, e especialmente, que a alta administração esteja empenhada com o cumprimento dos requisitos legais ou não (como melhoria contínua e prevenção da poluição) exigidos pela política (ABNT 2004). De acordo com La-Rovere (2001), a política ambiental diz respeito a um dos princípios básicos da gestão ambiental de uma empresa, sendo que a gestão ambiental, segundo Nilsson (1998), entre outros aspectos, pode servir de instrumento significativo nas relações da empresa com os stakeholders.

A função gerencial administração jurídico apresenta uma conduta ambiental forte, uma vez que o setor encarregado pelas questões relativas ao meio ambiente, entre outros aspectos, apresentou indicadores positivos em relação a todos os itens abordados nessa área estratégica, como: conhecimento da legislação ambiental aplicável; acompanhamento da legislação pelo responsável pela área do meio ambiente; realização de investimentos para controle dos efluentes líquidos e dos resíduos sólidos; não existência de multa/notificação do órgão de fiscalização ambiental nos últimos dois anos.

Quanto à área responsável pela administração financeira da empresa observa-se que a empresa em 2008 apresentou um investimento superior ao de 2007 para ser utilizado no sentido de se fazerem melhorias para o trato das questões ambientais. Mesmo assim, apresenta para essa função uma conduta ambiental fraca com tendência à intermediária, uma vez que apresentou apenas uma avaliação positiva em relação aos itens abordados, de um total de quatro. Observou-se ainda que a base utilizada para a definição do volume de investimentos é definido apenas para atender a legislação ambiental, que deveria ser feito considerando-se os objetivos e metas ambientais. Como a empresa em estudo ainda não definiu sua política ambiental, justifica-se que os seus investimentos 
não estejam direcionados para atender aos objetivos e metas ambientais inerentes às políticas ambientais de uma empresa.

Em relação à função administração de recursos humanos, considerando-se os parâmetros utilizados no modelo, apresenta uma conduta ambiental intermediária, pois apresenta um programa de educação ambiental informal e atua apenas de forma esporádica. A educação ambiental tem ganhado força perante as empresas na atualidade como uma ferramenta importante para a melhoria de desempenho socioambiental das organizações (Simons, 2006). Esse pensamento também é corroborado por Demajorovic (2003), porém, o autor alerta que se os objetivos empresariais não estiverem fundamentalmente voltados ao alcance do lucro do seu proprietário e dos acionistas, como enfatizado por muitas empresas, faz-se necessário o desenvolvimento de indicadores no qual os consumidores possam estimar os impactos positivos e negativos das condutas empresariais em âmbito financeiro, ambiental e social, permitindo que a educação corporativa seja desenvolvida em sua forma ampliada.

A função pesquisa e desenvolvimento apresentou uma conduta ambiental intermediária. Apesar de serem feitos investimentos na aquisição de equipamentos com um menor consumo de insumos, os seus produtos ainda não são certificados com o selo verde. Embora a empresa tenha informado da existência de tecnologias para minimizar impactos ambientais negativos ainda não possui em sua estrutura organizacional de um setor voltado para a pesquisa e desenvolvimento de novas tecnologias ambientais.

A função gerencial compras apresenta uma conduta ambiental forte, uma vez que adota padrões ambientais aos seus fornecedores de serviços. Os padrões ambientais utilizados nessa área dizem respeito às licenças de transporte, licenças ambientais e ao certificado de origem vegetal. Quanto à origem da matéria-prima, a empresa afirmou, conforme diagnóstico preliminar, que a organização tem coletado informações ambientais sobre seus fornecedores; tem discutido com os fornecedores a necessidade de se desenvolver estudos a respeito de seus respectivos impactos ambientais; tem o conhecimento se a matéria-prima é transportada adequadamente pelos seus fornecedores e sabe se o transporte empregado pelos fornecedores leva em conta os possíveis impactos ambientais.

A função gerencial Produção \& Manutenção apresenta uma conduta ambiental com tendência à intermediária. Os resultados alcançados nessa área foram: não existência de um Sistema de Gestão Ambiental, embora esteja nos planos da empresa implantá-lo; freqüência semestral das auditorias ambientais; os indicadores de performance ambiental foram definidos atrelados apenas aos padrões ambientais, o que deveria ser feito observando-se também outras unidades da empresa ou histórico de desempenho. Apesar da empresa não possuir um Sistema de Gestão Ambiental implantado, o 
diagnóstico preliminar identificou que a empresa encontra-se numa situação favorável a uma futura implantação, conforme diagnóstico inicial.

Para a função gerencial Marketing, observa-se pelos parâmetros utilizados uma conduta ambiental forte com tendência à intermediária. Apesar da existência de relatórios ambientais, estes estão atrelados ao atendimento da legislação ambiental; ainda não dispõe de uma sistemática para atendimento, acompanhamento e registro das reclamações ambientais das partes interessadas, pois essas funções ficam a cargo do chefe do laboratório, o que deveria ser parte do planejamento estratégico ambiental da empresa.

Para a função gerencial distribuição observou-se uma conduta ambiental intermediária, pois adotam apenas alguns critérios de prevenção dos riscos ambientais para a distribuição dos seus produtos, como licenças de transporte; direção defensiva; condições do veículo.

\subsection{Performance Ambiental da Empresa Estudo de Caso}

Os resultados da performance ambiental no período 2007/2008 podem ser melhor visualizados por meio da Quadro 4:

\begin{tabular}{|l|l|}
\hline \multicolumn{2}{|c|}{ Quadro 4 - Performance Ambiental da Empresa } \\
\hline Ar & \multicolumn{1}{c|}{ Monitoramento no Período (2007/2008) } \\
\hline Água & $\begin{array}{l}\text { Para esse compartimento foi apenas monitorado no } \\
\text { período o indicador acidificação. }\end{array}$ \\
\hline Solo & $\begin{array}{l}\text { Nesse período houve o monitoramento apenas do } \\
\text { indicador consumo de água nesse compartimento }\end{array}$ \\
\hline Fauna \& Flora & $\begin{array}{l}\text { Nesse compartimento houve o monitoramento dos } \\
\text { resíduos sólidos não perigosos apenas no ano de 2007. }\end{array}$ \\
\hline Recursos Energéticos & $\begin{array}{l}\text { Nesse compartimento não foi especificado como } \\
\text { ocorreu o monitoramento das espécies animais e } \\
\text { vegetais contaminadas. }\end{array}$ \\
\hline
\end{tabular}

Fonte: Pesquisa de Campo (2009)

Os resultados evidenciam que a empresa está apenas começando o processo de quantificação da performance ambiental, o que corrobora com uma conduta ambiental intermediária. Percebe-se ainda que não existe um sistema de informações na empresa que possa disponibilizar de forma efetiva as informações ambientais para o conhecimento dos públicos interessados e para a tomada de decisão empresarial.

\subsection{Pressões da Estrutura da Indústria}

O Quadro 5 mostra os resultados obtidos para a pressão da estrutura da indústria. 


\begin{tabular}{|l|c|c|}
\hline \multicolumn{1}{|c|}{ Quadro 5 - Pressão da Estrutura da Indústria } \\
\cline { 2 - 3 } Características da Estrutura da Indústria & Alta & Baixa \\
\hline $\begin{array}{l}\text { Impacto ambiental inerente ao processo produtivo e variável } \\
\text { com a escala de produção e a tecnologia adotada }\end{array}$ & & X \\
\hline Legislação Ambiental & & $\mathbf{X}$ \\
\hline Exigências Ambientais das Partes Interessadas & & $\mathbf{X}$ \\
\hline
\end{tabular}

Fonte: Pesquisa de Campo (2009)

As Pressões da Estrutura da Indústria Sucroalcooleira, conforme metodologia de Abreu (2011), foi averiguada observando os impactos ambientais do processo produtivo, a legislação ambiental aplicável à atividade sucroalcooleira e às exigências ambientais das partes interessadas.

Conforme pesquisa de campo os impactos ambientais do processo produtivo da empresa podem ser considerados baixos, uma vez que a destinação da vinhaça é reutilizada como forma de adubo e o bagaço da cana é destinado a co-geração de energia.

A empresa em estudo não sofreu nenhuma multa/notificação dos órgãos de físcalização ambiental no período 2007/2008, indicando uma baixa pressão da estrutura da indústria para o indicador legislação ambiental.

Quanto ao indicador exigências ambientais das partes interessadas, observou-se uma baixa pressão em que a ênfase foi dada para o licenciamento ambiental que se exige para empresas pertencentes ao setor sucroalcooleiro.

\subsection{Posicionamento Estratégico Ambiental}

O Posicionamento Estratégico Ambiental é obtido quando se correlaciona a Conduta Ambiental da Empresa (Tabela 1) com as pressões da Estrutura da Indústria (Quadro 1), conforme Figura 2.

Figura 2 - Posicionamento Estratégico da Empresa

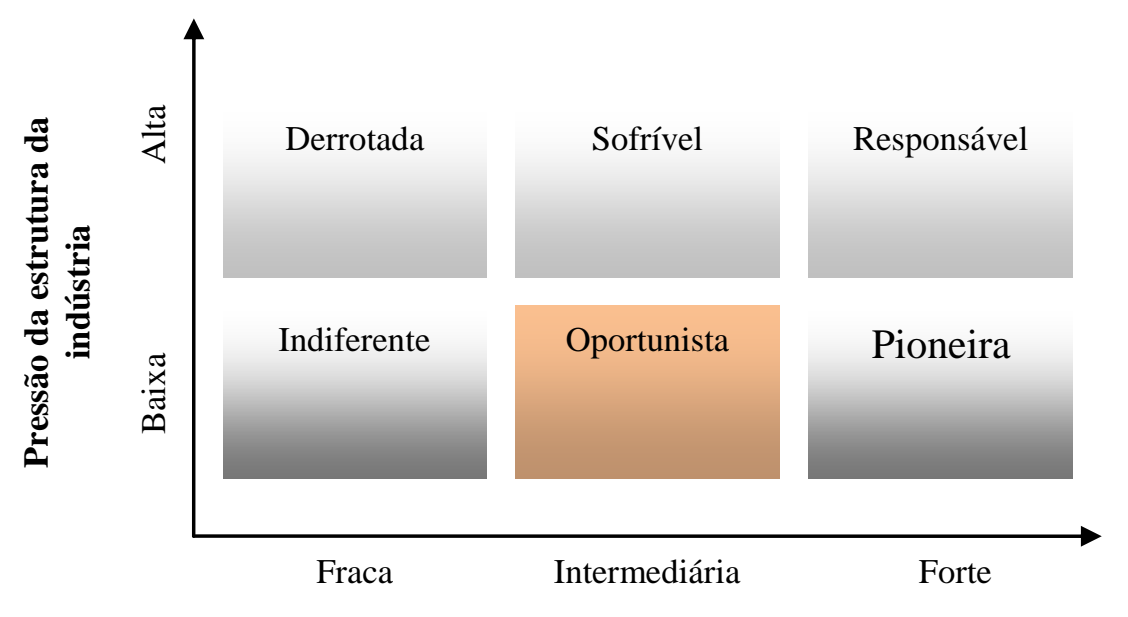

Conduta Ambiental

Fonte: Pesquisa de campo (2009) 
Uma empresa oportunista apresenta baixa pressão da estrutura da indústria e uma conduta ambiental intermediária. Segundo Abreu (2001), uma empresa que apresenta este posicionamento estratégico está à procura da vantagem competitiva que outras empresas concorrentes já atingiram.

O ideal seria que mesmo submetida à baixa pressão da estrutura da indústria, a empresa apresentasse uma conduta ambiental forte, pois as empresas pioneiras são as primeiras a identificarem uma vantagem competitiva e tomar atitudes proativas frente à concorrência, que lhes garanta entre outros benefícios competitivos: a redução de custos totais; imagem positiva perante os stakeholders - chave (clientes, órgãos ambientais, comunidade, poder público, funcionários); participação em negócios internacionais com exigências ambientais elevadas.

\section{Considerações Finais}

O modelo Estrutrura-Conduta-Performance-Ambiental (ECP-AMBIENTAL) se insere no campo teórico conhecido como Estrutura-Conduta-Performance (ECP). Partindo desse campo teórico, o ECP-AMBIENTAL se consubstancia como uma importante ferramenta de tomada de decisão no que se refere ao posicionamento atual das empresas e ainda contribui no sentido de ajudá-las a desenharem o posicionamento futuro que tenham por meta.

O modelo chama a atenção para as dimensões: impacto ambiental inerente ao processo produtivo; legislação ambiental e exigências ambientais das partes interessadas como elementos importantes da pressão da estrutura da indústria a serem observados pela empresa. Dessa forma, classifica essa pressão como sendo baixa ou alta. O modelo também classifica a conduta ambiental da empresa em fraca, intermediária e forte. Por fim, as pressões da estrutura da indústria em confronto com a conduta ambiental da empresa determinam um dos seguintes posicionamentos estratégicos: derrotada, sofrível, responsável, indiferente, oportunista e pioneira.

Esse modelo ao utilizar em sua estrutura indicadores presentes nos elementos ar, água, solo, recursos naturais, fauna \& flora, bem como indicadores inseridos em vários modelos e ferramentas ambientais, amplia o seu escopo como instrumento que possa contribuir para que as empresas vislumbrem um posicionamento estratégico favorável à responsabilidade social corporativa.

O modelo evidencia que uma postura que venha a contribuir com um posicionamento estratégico responsável deve estar vinculada a alta pressão da estrutura da indústria e uma conduta ambiental forte. Entretanto, para que uma empresa tenha uma conduta ambiental forte faz-se necessário que ela amplie os indicadores ambientais presentes em modelos e ferramentas de gestão ambiental em seu sistema de negócios.

Os resultados de uma pesquisa devem gerar insight para futuras pesquisas, especialmente quando se trata de estudo de caso único e holístico, que certamente não condiz com outros 
contextos pesquisados. Assim, para o avanço do conhecimento científico, sugere-se que a metodologia aplicada nessa pesquisa seja verificada em outras empresas do setor sucroalcooleiro, em outros setores produtivos, e ainda que sejam ampliados os indicadores ambientais em cada modelo e ferramenta ambiental utilizado nesse estudo para verificação do posicionamento estratégico ambiental da empresa.

\begin{abstract}
In recent years, aspects related to environmental problems and use of natural resources became a concern for companies both in terms of opportunity to improve the way it operates, as a business opportunity, and contribute to sustainability. This sense is emerging models and environmental management tools, among them, corporate social responsibility, applied within a strategic posture. In this context, the aim of this study is to identify the positioning strategy used by a distillery, with a view to corporate social responsibility. To achieve this goal, we used the model-Structure-ConductPerformance Environmental Abreu (2011). We conducted a descriptive field where they performed a case study in an alcohol distillery in the state of Paraiba. The techniques used in the research were: literature search, semi-structured and non-participant observation. Results indicated an intermediate environmental conduct of the company and, even when this behavior correlates with the environmental pressures of the industry structure, the company is in a strategic position opportunistic environmental.
\end{abstract}

Key-words: environmental practices, strategic positioning, corporate social responsibility.

\title{
Referências
}

ABREU, Mônica Cavalcanti Sá de. Modelo de avaliação da estratégia ambiental: uma ferramenta para a tomada de decisão. Tese (Doutorado em Engenharia de Produção) Universidade Federal de Santa Catarina, Florianópolis/SC, 2001, 218 p.

ASSOCIAÇÃO BRASILEIRA DE NORMAS TÉCNICAS. NBR ISO 14001: Sistemas da gestão ambiental Requisitos com orientações para uso. Rio de Janeiro, 2004.

BARBIERI, José Carlos. Gestão ambiental empresarial: conceitos, modelos e instrumentos. São Paulo: Saraiva, 2007.

BORGER, Fernanda Gabriela. Responsabilidade corporativa: a dimensão ética, social e ambiental na gestão das organizações. In: VILELA JR., Alcir; DEMAJOROVIC, Jacques.(Orgs.) Gestão ambiental: desafios e perspectivas para as organizações. São Paulo: Editora SENAC, 2006. cap. 1, p. 13 - 40.

CARROLL, A. Corporate social responsibility. Business and Society, v.8, n. 3, p. 268-295, 1999.

cross

CONSELHO EMPRESARIAL BRASILEIRO PARA O DESENVOLVIMENTO SUSTENTÁVEL.(CEBDS). Produção mais limpa: barreiras. Disponível em: 〈http://www.cebds.org.br/cebds/eco-pmaisl-barreiras.asp〉. Acesso em: 14 set. 2008.

DEMAJOROVIC, Jacques. Sociedade de risco e responsabilidade socioambiental: perspectivas para a educação corporativa. São Paulo: Editora Senac, 2003.

Ecoeficiência em serviços: diminuindo impactos e aprimorando benefícios ambientais. In: VILELA JR., Alcir; DEMAJOROVIC, Jacques.(Orgs.) Gestão ambiental: desafios e perspectivas para as organizações. São Paulo: Editora Senac, 2007. cap. 6, p. 169-198. 
DIAS, Reinaldo. Marketing ambiental: ética, responsabilidade social e competitividade nos negócios. São Paulo:

Atlas, 2007.

ENDERLE, G.; TAVIS, L. A. Balanced concept of the firm and measurement of its long-term planning and performance. Journal of Business Ethics, v.17, n.11, p.1129-1144, 1998.

cross ref

FROES, César; MELO NETO, Francisco Paulo de. Responsabilidade social \& cidadania empresarial: a administração do terceiro setor. Rio de Janeiro: Qualitymark, 1999.

LA ROVERE (coord.). Manual de auditoria ambiental. Rio de Janeiro: Qualitymark, 2001.

NILSSON, W. R. Services instead of products: experiences from energy markets - examples from Sweden. In: MEYER- KRAHMER, F. (Ed.). Innovation and sustainable development: lessons for innovation policies. Heidelberg: Physica - Verlag, 1998.

PHILIPPI JR. Arlindo; AGUIAR, Alexandre de Oliveira e. Auditoria ambiental. In: PHILIPPI JR. Arlindo; ROMÉRO, Marcelo de Andrade; BRUNA, Gilda Collet. Curso de gestão ambiental. Barueri (SP): Manole, 2004.

PORTER, M.; LINDE, C. Green and competitive: ending the stalemate. In: Harvard Business Review, Sep./Oct. 1995.

QUAZI, A.; O'BRIEN, D. An empirical test of a cross-national model of corporate social responsibility. Journal of Business Ethics, v.25, p.33-51, 2000.

cross ref

SÁNCHEZ, Luis Enrique. Avaliação de impacto ambiental e seu papel na gestão de empreendimentos. In: VILELA JR., Alcir e DEMAJOROVIC, Jacques (Orgs.). Gestão ambiental: desafios e perspectivas para as organizações. São Paulo: Editora SENAC, 2006. Cap. 3, p. 85-104.

SEIFFERT, Mari Elizabete Bernardini. Gestão ambiental: instrumentos, esferas de ação e educação ambiental. São Paulo: Atlas, 2007.

SIMONS, Mônica Osório. Educação ambiental na empresa: mudando uma cultura. In: VILELA JR., Alcir e DEMAJOROVIC, Jacques (Org.). Modelos e Ferramentas de Gestão Ambiental: desafios e perspectivas para as organizações. São Paulo: Editora Senac, 2006. cap. 07, p.199-218.

VERGARA, Sylvia Constant. Projetos e Relatórios de Pesquisa em Administração. São Paulo: Atlas, 1997.

WARTICK,CROCHAN, P. The evolution of corporate social performance model. Academy of Management Review, v.10, n. 4, p.758-769, 1985.

cross ref

WOOD, D. Corporate social performance revisited. Academy of Management Review, v.16, n.4, p. 691-718, 1991 cross ref

YIN, Robert K. Estudo de Caso: planejamento e métodos. 3. ed. Porto Alegre: Bookman, 2005.

\section{Dados dos autores:}

\section{Nome completo: Maria de Fátima Nóbrega Barbosa}

Filiação Institucional: Universidade Federal de Campina Grande

Departamento: Ciências Contábeis

Função ou cargo ocupado: Professora Adjunta I 
Endereço completo para correspondência: Rua Paulo Pontes, 260, Bairro: Centenário, CEP: 58428210, Campina Grande - PB

Telefones para contato: (083) 3333-5629/(083) 99726799

e-mail:mfnbarbosa@yahoo.com.br

Nome completo: Gesinaldo Ataíde Cândido

Filiação Institucional: Universidade Federal de Campina Grande

Departamento: Administração

Função ou cargo ocupado: Professora Titular em Administração Geral

Endereço completo para correspondência: Rua Infante Dom Henrique, 380/301, Tambaú, CEP: 58039-150, João Pessoa - PB

Telefones para contato: (083) 2101-1484/ (083) 88530009

e-mail: gacandido@uol.com.br

Enviado em: 02/05/212

Aprovado em: 13/07/2012 